\title{
Holistic view of training of intrapartum fetal monitoring and importance of its content.
}

Shashikant Sholapurkar ${ }^{1}$

${ }^{1}$ Royal United Hospital NHS Trust

April 26, 2021

\section{Hosted file}

2021.04.15 resubmission manuscript BJOG letter CTG training.pdf available at https:

//authorea.com/users/325190/articles/519579-holistic-view-of-training-of-intrapartum-

fetal-monitoring-and-importance-of-its-content 